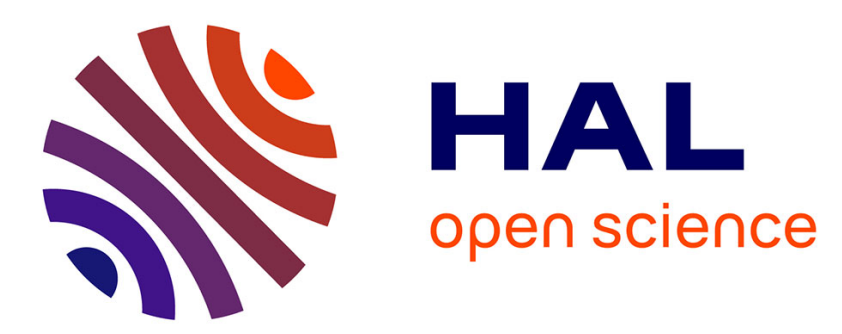

\title{
Towards robust methods to couple lumped rainfall-runoff models and hydraulic models: A sensitivity analysis on the Illinois River
}

J. Lerat, Charles Perrin, Vazken Andréassian, C. Loumagne, Pierre Ribstein

\section{- To cite this version:}

J. Lerat, Charles Perrin, Vazken Andréassian, C. Loumagne, Pierre Ribstein. Towards robust methods to couple lumped rainfall-runoff models and hydraulic models: A sensitivity analysis on the Illinois River. Journal of Hydrology, 2012, 418-419, p. 123 - p. 135. 10.1016/j.jhydrol.2009.09.019 . hal00732342

\section{HAL Id: hal-00732342 \\ https://hal.science/hal-00732342}

Submitted on 14 Sep 2012

HAL is a multi-disciplinary open access archive for the deposit and dissemination of scientific research documents, whether they are published or not. The documents may come from teaching and research institutions in France or abroad, or from public or private research centers.
L'archive ouverte pluridisciplinaire $\mathbf{H A L}$, est destinée au dépôt et à la diffusion de documents scientifiques de niveau recherche, publiés ou non, émanant des établissements d'enseignement et de recherche français ou étrangers, des laboratoires publics ou privés. 


\title{
Towards robust methods to couple lumped rainfall-runoff models and hydraulic models:
} A sensitivity analysis on the Illinois River

\author{
Julien Lerat $^{a}$, Charles Perrin ${ }^{\mathrm{a}, *}$, Vazken Andréassian ${ }^{\mathrm{a}}$, \\ Cécile Loumagne ${ }^{\mathrm{a}}$, Pierre Ribstein ${ }^{\mathrm{b}}$ \\ ${ }^{a}$ Cemagref, Hydrosystems research unit, Parc de Tourvoie, 92163 Antony Cedex, \\ France \\ ${ }^{\mathrm{b}}$ UPMC Univ Paris 06, UMR 7619 Sisyphe, Case 105, 4 Place Jussieu, 75252 \\ Paris, Cedex 05, France
}

\begin{abstract}
Accurate prediction of a flood inundation area constitutes an essential part of a flood forecasting system. When a river reach receives significant lateral inflows, flood inundation modelling requires the joint application of a hydrological model to calculate lateral inflows and a hydraulic model to calculate water levels along the river reach. In this study, we compared different strategies to couple the GR4J lumped rainfall-runoff model and the linearized diffusive wave propagation model. These strategies introduced variations in the nature of the connections between the two models using combinations of point and uniformly distributed lateral inflows. The coupled model was then applied to the Illinois River case study for which 10 years of hourly data were made available within the Distributed Model Intercomparison Project, now in phase 2. The simulations were assessed at the downstream
\end{abstract}


end of the reach and at two interior points considered to be ungauged during the calibration process.

The results first show that including uniformly distributed inflows made the coupled model more robust and stable compared to only using point flow input. A similar level of performance was reached with models using point inflows only, but at the cost of more uncertain parameters and less stable model performance when changing test periods. Second, identifying the optimal number of tributaries to be modelled individually by the hydrological model was easier when a combination of uniformly distributed and point inflows was used. In this case, model performance was less sensitive to the number of tributaries used and the inclusion of two or three tributaries appeared sufficient to obtain satisfactory performance for the simulations on the main channel. Last, the results on the main channel differed from those obtained on tributaries: overall performance was better on the main channel and required a lower degree of lateral inflow resolution, which suggests that upstream flow measurements provide much more valuable information for flow simulation on ungauged points.

Key words:

Hydrological Model, Hydraulic Model, Model Coupling, Lateral Inflows, Semi-Distribution

\section{Introduction}

The United States National Weather Service (NWS) initiated the Distributed Model Intercomparison Project (DMIP), now in phase 2, to enhance the use of distributed rainfall-runoff $(\mathrm{RR})$ models in the context of real-time flood

* Corresponding author.

Email address: charles.perrin@cemagref.fr (Charles Perrin). 
5 forecasting (Smith et al., 2009, this issue). Within a flood forecasting system, such models can be connected to a hydraulic model in order to calculate the extent of the inundation area and facilitate the dissemination of flood warnings.

Although distributed models are more and more widely used, they are still subject to problems such as data requirements and parameter identifiability, which may limit their robustness and their adequacy for operational purposes. Besides, it has not been clearly demonstrated that their greater complexity (in comparison to simpler approaches) contributes additional model efficiency (Michaud and Sorooshian, 1994; Refsgaard and Knudsen, 1996; Savenije, 2001; Smith et al., 2004; Te Linde et al., 2008). Therefore the use of lumped RR models still remains a valuable alternative in the analysis of rainfall-runoff transformation at the catchment scale (Sivapalan et al., 2003; Young, 2003) and for proposing robust methods to couple these models with hydraulic models.

Lumped RR models can be considered conceptual, whereas hydraulic models are often viewed as physically based. Connect these two kinds of model raises a number of scientific and technical issues, as will be discussed hereafter. However, the scientific literature is surprisingly lacking in studies focusing on model coupling, although several authors (Klemes, 1983; Robinson and 25 Sivapalan, 1995) have pointed out the importance of doing so. As indicated by Robinson and Sivapalan (1995): "the work towards finding connections between the physically based and conceptual models has been inadequate, although this is precisely what is required for the advancement of hydrological modeling for predictive purposes." 
To our knowledge, there are no clear guidelines on this issue available for services that routinely develop and use such models. This article investigates this issue by focusing on two main questions:

(1) What type of lateral inflow scheme should be used? Point or uniformly distributed? In various hydraulic software packages such as HEC-RAS (USACE, 2002) and MIKE11 (Havnø et al., 1995), lateral inflows can be defined as point or uniformly distributed. Point inflows occur at confluences between the main river reach and its tributaries. Uniformly distributed inflows encompass all water fluxes between the river reach and its neighbourhood. This second type of inflow is a very common concept for hydraulic engineers but remains difficult to grasp for hydrologists: it can represent contributions from small tributaries grouped together, distributed contributions from lateral hill slopes, bank storage effects or exchanges with groundwater (Birkhead and James, 2002). A review of the literature in Section 2 shows that few hydrologists have developed semi-distributed models that can handle both types of lateral conditions.

(2) How many lateral tributaries should be accounted for? If we use lumped models to calculate lateral contributions, we need to identify a set of tributaries that will be modelled independently. The question is not easy to answer because it is well known that more spatially detailed models do not always show better performance (Beven, 1996; Refsgaard, 1997; Boyle et al., 2001; Das et al., 2008). The impact of spatial resolution on model performance has been thoroughly studied for distributed and semidistributed models (Wood et al., 1988; Vieux, 1993; Koren et al., 1999; Vázquez et al., 2002; Liang et al., 2004), but, to the authors' knowledge, no article deals explicitly with the question of lateral inflow resolution 
for a hydraulic model.

These two questions were investigated on a $95-\mathrm{km}$ reach of the Illinois River located within the DMIP 2 study area (see Figure 1 and Section 3) for which hourly rainfall and streamflow data were available (see DMIP 2 website, www.weather.gov/oh/hrl/dmip/2/). On this river reach, two gauging stations are located between the upstream and downstream ends of the reach: one is located on the Illinois River and the other on a tributary (Flint Creek) close to its confluence with the Illinois River. This gauging network provides the opportunity to evaluate model performance (1) at the downstream end of the reach (calibration target), (2) on a point located within the reach and (3) on a tributary that provides a substantial lateral contribution.

Although flood forecasting was mentioned previously, this paper will only deal with flow simulation. Assimilation routines such as the Kalman filter updating scheme can strongly influence the models' behavior and could blur our understanding of the role of the different model components. Therefore model updating and streamflow data assimilation algorithms are not considered here.

The main objective of the study was to provide a sensitivity analysis of the performance of a flow simulation model (coupling a lumped RR model and a propagation model) to the type and spatial resolution of inflows produced by the RR model. We chose specific models for this study and tested them on the single case of the Illinois River. However, the sensitivity analysis only focused on model coupling strategies without modifying the model's structure. As a result, the study should be relevant to other semi-distributed models including a lumped RR module connected to a routing module.

Section 2 presents a review of the literature. A short description of the Illinois 
catchment, used as a case study, is provided in Section 3. Then, the various options considered in model coupling are presented in Section 4. Last, Section 5 details and discusses the results obtained.

\section{Questions Related to Coupling Rainfall-Runoff and Hydraulic Models}

Coupling RR models and fully dynamic hydraulic models has not been frequently reported in the literature. Knebl et al. (2005), Moramarco et al. (2005), Whiteaker et al. (2006) and Lian et al. (2007) present examples of such coupling but they do not address the two issues raised in the introduction: the formulation of lateral inflows in the hydraulic model as point and/or uniformly distributed inflows and their level of spatial aggregation.

\subsection{Point vs uniformly distributed lateral inflow scheme}

Since the pioneering work of Hayami (1951), several authors have used simplifications of the Saint-Venant system to derive analytical formulations of point and uniformly distributed lateral inflows (Moussa, 1996; Moramarco et al., 1999; Fan and Li, 2006). Moussa (1996) presented an analytical solution obtained by a linearisation of the diffusive wave equation and the Laplace transform and integrated this solution into a semi-distributed RR model (Moussa, 1997) that handles both types of inflow. Another example of this approach 100 is given by Koren et al. (2004), who used uniformly distributed lateral inflow boundary conditions in their distributed model.

Apart from these few examples, the majority of the studies in which a semi- 
distributed model is applied do not distinguish between point and distributed lateral inflows (Krysanova et al., 1999; Boyle et al., 2001; Onyando et al., 2003; Ajami et al., 2004; Zhang et al., 2004). When coupling RR models with a full hydraulic model, this point becomes critical since the two types of inflow are not equivalent when numerically solving the Saint-Venant equations: point inflows introduce discontinuities in the mass conservation equation that can lead to numerical instabilities. Conversely, uniformly distributed lateral inflows fit well with the partial derivative equation system.

\subsection{What Level of Spatial Aggregation Should Be Chosen?}

Many authors discuss the appropriate level of spatial discretisation in a RR modelling context, i.e. the number of sub-catchments or the size of computational grid that should be used to maximize model performance. Refsgaard and Knudsen (1996), on three catchments in Zimbabwe ranging from 240 to $1090 \mathrm{~km}^{2}$, as well as Ajami et al. (2004) on the Illinois basin at Watts (1645 $\mathrm{km}^{2}$ ), did not find significant improvement when shifting from a lumped model to a semi-distributed model for catchment outlet simulations. With similar tools and objectives, Boyle et al. (2001) reported a substantial gain in performance when shifting from a lumped to a three-sub-catchment semi-distributed model, but no additional gain could be achieved with an eight-sub-catchment distribution on the Blue River catchment $\left(1227 \mathrm{~km}^{2}\right)$. Butts et al. (2004) report similar results based on coupling lumped RR models and different routing schemes including a fully dynamic model on the same catchment. This point is important here since it suggests the existence of a plateau in model performance when model distribution is refined. This is further investigated here for 
lateral inflow distribution.

Another important point discussed by Boyle et al. (2001) is the comparison between the distribution of model parameters and rainfall inputs. They concluand many small ones. This is confirmed by the changes in the drained area from the Savoy station down to the Tahlequah station along the main river channel (see Figure 1.d). 
All the data processed to force and calibrate the models were provided by the Hydrology Laboratory of the National Weather Service (see Smith et al., 2009, this issue).

- The sub-catchment area and boundaries were calculated from the 15 arcsecond digital elevation model (DEM) processed by the National Operational Hydrologic Remote Sensing Center.

- Ten years of hourly mean areal rainfall were calculated by intersecting NEXRAD gridded data and sub-catchment boundaries as defined by the DEM.

- Ten years of hourly streamflow data were provided by the USGS for the Tahlequah, Savoy, Siloam Springs (situated at the middle of the river reach between Savoy and Tahlequah) stations and the Kansas station located on Flint Creek. Flint Creek is the second largest tributary (number 2 on Figure $1 . b)$ to the main river reach. Note that data on interior points were provided by the National Weather Service at the end of the DMIP 2 project, after the simulations had been submitted to this experiment by the participants. We did not use them to generate simulations for the Oklahoma experiment (see Smith et al., 2009, this issue).

- Twelve mean monthly values of potential evapotranspiration (PE) were extracted from NOAA seasonal maps covering the whole Tahlequah catchment.

The event-based statistics on flow simulations were calculated on 15 events selected in the list provided by the National Weather Service (Reed et al., 2004). These events were chosen to be common for the four gauging stations: Savoy, Kansas, Siloam Springs and Tahlequah. The selected events are listed in Table 1. 


\section{Options Available to Couple Lumped Rainfall-Runoff Models and Hydraulic Models}

In this section, we present the different options to couple lumped RR models simulating lateral inflows contributions to the main river, and a hydraulic model. Figure 2 shows the scheme applied to couple the two models: for the sake of simplicity, we now consider a river reach between two gauging stations. This reach receives several tributaries. Propagation along the reach is handled by a hydraulic model and lateral contributions are calculated by lumped RR models using mean areal rainfall on lateral sub-catchments. The coupled model is only calibrated against measured streamflows at the downstream end of the reach (here the Tahlequah station).

Here measured flows at the upstream station (Savoy) were used as an upstream boundary condition for the hydraulic model. This differs significantly from the DMIP project protocol where no streamflow data should be used upstream of the calibration point. We used a measured upstream boundary condition to avoid introducing additional errors coming from upstream simulations and to concentrate on the river reach itself.

\subsection{Description of the two coupling options}

As indicated in the previous sections, the first question investigated in this paper focuses on the formulation of lateral inflows as point or uniformly distributed. Accordingly, the different coupling options will be split in two: 
(1) Options that consider both types of inflows: in these options, contributions from a number of tributaries are injected into the hydraulic model in the form of point inflows located at their confluences with the main river. The contribution from the remaining area (called the "intermediate area" on Figure 2) is injected as uniformly distributed lateral inflows along the whole river reach. All these contributions are simulated by the RR models.

(2) Options that do not consider uniformly distributed lateral inflows: In these options, only point lateral inflows are considered. Hence, the contribution from the intermediate area, injected in the form of a uniformly distributed inflow in the previous option, is not taken into account here. To avoid an underestimation of calculated streamflows in this option, each tributary contribution is multiplied by a scaling factor $\alpha$ according to the following equation.

$$
\begin{aligned}
Q_{i}^{*} & =\alpha Q_{i} \\
\alpha & =\frac{S_{\text {Down }}-S_{U p}}{\sum_{i=1}^{N} S_{i}}
\end{aligned}
$$

where $Q_{i}$ is the contribution from the $i^{\text {th }}$ tributary calculated by the RR model, $Q_{i}^{*}$ the point inflow injected in the hydraulic model, $S_{i}$ is the catchment area of the $i^{\text {th }}$ tributary, $S_{U p}$ and $S_{\text {Down }}$ are the areas of the upstream and downstream gauging station catchment, respectively, and $N$ is the total number of tributaries considered in this configuration. $S_{\text {Down }}-S_{U p}$ represents the total area drained by the river reach between the two stations.

The second option might appear coarse, especially with one or two tributaries as lateral inflows: the actual contribution from these sub-catchments may be excessively increased by the scaling factor, resulting in unbalanced simulations over the river reach. However, eliminating uniformly distributed inflows does 
not leave many options to properly reproduce the distribution of inflows along the river reach with a defined number of inflow points. As a result, the second option should be regarded here as a comparative reference rather than a reliable solution in coupling $\mathrm{RR}$ and hydraulic models.

225 The spatial aggregation of lateral inputs constitutes the second important aspect investigated in this study: for each option presented previously, the number of contributions coming from tributaries in the form of point lateral inflow is gradually increased from 1 to 6 . Figure 3 shows the first four discretisation levels. Tributaries are considered by decreasing order of catchment size 230 at the confluence with the main channel, as shown in Figure 1.b. The rationale behind this ordering is to start with the main lateral contribution and to progressively refine the definition of point lateral inflows. Of course, catchment size may poorly reflect the magnitude of contributions from the tributaries, as small catchments with impermeable soils may bring more water than large ones. This point will be discussed in Section 5.2.

Note that the simulations at the Kansas station cannot be calculated by the coupled model when the configuration does not explicitly include tributary no. 2 as a point inflow. Kansas is located near the catchment outlet of this tributary; the simulation at this point is then conditional on the existence of the corresponding contribution.

\subsection{Lumped Rainfall-Runoff Model}

We used the continuous lumped GR4J RR model to calculate lateral inflows. This model has been applied over a wide range of hydro-climatic condi- 
tions (Perrin et al., 2003) and used in the MOPEX experiment of rainfall-runoff

models intercomparison (Andréassian et al., 2006). Streamflows are calculated from mean areal rainfall and potential evapotranspiration (PE) time series. The calculations are made in three steps: first, the effective rainfall is calculated with a zero capacity interception store and a soil moisture accounting store. Second, this effective rainfall is split into two components: one routes $90 \%$ of effective rainfall with a unit hydrograph $U H 1$ and a nonlinear routing store; the other routes the remaining $10 \%$ with a second unit hydrograph $U H 2$. Third, an intercatchment groundwater flow function is computed to account for water gains or losses stemming from interactions with neighbouring catchments or groundwater and is added to both components. The final discharge 255 at the catchment outlet is calculated as the sum of both flow components. Figure 4 presents the overall model scheme. Perrin et al. (2003) provide further mathematical details. The four parameters to be calibrated are the following.

(1) $S$, the capacity of the soil moisture store (in millimetres).

(2) IGF, the parameter that controls the intercatchment groundwater flows (in millimetres). Positive values indicate water imports from groundwater or neighbouring catchments; negative values indicate water exports.

(3) $R$, the capacity of the routing store (in millimetres).

(4) $T B$, the time base of the unit hydrograph (in hours). This parameter controls the time lag between effective rainfall and runoff peaks.

\subsection{Linearised Diffusive Wave Hydraulic Model}

We selected the linear diffusive wave as the propagation model in this study. Under some assumptions, the Saint-Venant system combining continuity equa- 
tions of mass and momentum can be simplified. The inertia terms of the momentum equation can be neglected if they are small compared to the channel bed slope leading to the diffusive wave approximation. Flow motion is then described by the following equation (Moussa, 1996):

$$
\frac{\partial Q}{\partial t}+C\left(\frac{\partial Q}{\partial x}-q\right)-D\left(\frac{\partial^{2} Q}{\partial x^{2}}-\frac{\partial q}{\partial x}\right)=0
$$

with $t$ the time, $x$ the abscissa along the river reach, $Q(x, t)$ the discharge, $q(x, t)$ the lateral inflows, $C$ the wave celerity and $D$ the diffusion coefficient. If the equation is further linearised around a reference regime, $C$ and $D$ can be considered to be constant. Hayami (1951) identified an analytical solution for this equation in the case where $q=0$. This solution takes the form of a convolution product applied to an input $I(t)=Q(0, t)-Q(0,0)$ and giving an output $O(t)=Q(L, t)-Q(L, 0)$ as:

$$
\begin{aligned}
& O(t)=\int_{0}^{t} I(t-\tau) K(\tau) d \tau \\
& K(t)=\frac{L}{2 \sqrt{\pi D}} \frac{\exp \left[\frac{C L}{4 D}\left(2-\frac{L}{C t}-\frac{C t}{L}\right)\right]}{t^{3 / 2}}
\end{aligned}
$$

where $\mathrm{L}$ is the length of the river reach, $K$ the convolution kernel and $\tau$ a dummy variable. In the case of uniformly distributed lateral inflows (i.e. $q(x, t)=q(t))$, Moussa (1996) identified the following analytical solution for the same equation:

$$
\begin{aligned}
& \begin{array}{l}
O(t)=\Psi(t)+\int_{0}^{t}[I(t-\tau)-\Psi(t)] K(\tau) d \tau \\
\text { with: } \Psi(t)=L \int_{0}^{t} q(t) d \tau
\end{array}
\end{aligned}
$$

This solution was applied by several authors (Baptista and Michel, 1989; Corradini, 1991; Moramarco et al., 2005) to model propagation in natural river 
channels. It has two main limitations. First, the analytical solution of Equation 3 is valid only for constant values of $C$ and $D$, which reduces its precision compared to a fully dynamic model. Second, it does not handle downstream boundary conditions and hence neglects all backwater effects.

Compared to other simplified routing schemes, it has the following advantages. First, it accepts point and uniformly distributed lateral inflows, which is of primary importance in this study. Second, it can calculate flows along the entire reach allowing interior simulations to be evaluated (see Section 4.5). Finally, the convolution product makes model execution very fast. This greatly facilitates calibration of the coupled models that may require a significant number of iterations.

Although the linearised diffusive wave is based on the Saint-Venant equations, it is clear that this solution is not equivalent to a fully dynamic model. So it should be necessary to check that similar results are obtained with refined hydraulic models. This point will not be investigated in this paper. The work of Butts et al. (2004), conducted on the Blue River catchment during DMIP 1, provides an encouraging example on the usefulness of simplified routing schemes: they compared two routing procedures in a semi-distributed model and found that a Muskingum-Cunge routing model was equivalent to a full dynamic model. This suggests that the benefits of complex hydraulic models are not so important in semi-distributed hydrological modelling. 


\subsection{Model Inputs and Parameterisation} parameter distribution (see e.g. Ajami et al., 2004; Andréassian et al., 2004; Zhang et al., 2004). Accordingly, the modelling scheme adopted here relies on the following elements:

- Mean areal rainfall is calculated from gridded rainfall data (see Section 3) 325 for each sub-catchment. This means that $\mathrm{N}$ distinct hourly rainfall time series are used as input to the $\mathrm{N}$ lateral sub-catchment models.

- The same set of GR4J parameters is used for all sub-catchments. As a result, only six parameters have to be calibrated: the four parameters of the GR4J model and the two parameters of the linearised diffusive wave model. The main advantage of this parameterisation scheme is to maintain the same number of calibrated parameters for all coupling options. As a result, differences in performance cannot be attributed to variations in the 
number of degrees of freedom.

The estimation of parameter values of lumped RR models requires calibra-

tion because they generally do not have measurable counterparts in the field.

Conversely, the hydraulic model selected here may be considered to be physically based, with measurable parameters. Nonetheless, we calibrated its two parameters (C and D) for two reasons. First, relations to calculate celerity and diffusion from channel geometry and Manning roughness exist (Baptista and Michel, 1989), but they only apply to rectangular or prismatic channels. These relations cannot be used in natural rivers such as those considered here. Second, it is interesting to check whether calibration leads to acceptable hydraulic parameters.

\subsection{Model Calibration and Validation}

As presented in Figure 2, coupled models are calibrated to match only calculated and observed streamflows time series at the downstream end of the river reach (at the Tahlequah station). Data from the intermediary gauging stations (Siloam Springs and Kansas) were never used in the calibration phase. Model inputs were streamflows measured at the upstream gauging station (Savoy) as well as areal rainfall and potential evapotranspiration obtained on each lateral sub-catchments.

The different model configurations were calibrated with a Levenberg-Marquardt algorithm using the Nash and Sutcliffe (Nash and Sutcliffe, 1970) efficiency criterion $(N S E)$ calculated at the Tahlequah station as a single objective 355 function. The models were tested following a split sample test (Klemes, 1986) 
using the two sub-periods defined in the DMIP protocol (Smith et al., 2009) including 1 year of warm-up (sub-period P1 started on 1995-10-01 and ended on 2002-09-30, sub-period P2 started on 2001-10-01 and ended on 2006-09-30). The models were calibrated on the first period and validated on the second one, and then the role of the two periods was reversed to evaluate the models in validation mode on all data at hand. The mean statistics obtained over the two validation and calibration tests were considered for performance analysis.

For each period, NSE as well as statistics on 15 flood events (see Section 3) were calculated on three gauging stations: at the downstream end of the reach 365 (Tahlequah), on an interior point located at the middle of the reach (Siloam Springs) and on one tributary (Kansas).

Event-based statistics were calculated according to Smith et al. (2004):

$$
\begin{array}{r}
\text { Absolute peak error (\%): } E_{P}=\frac{\sum_{k=1}^{N_{e}}\left|Q_{P k}-Q_{P S k}\right|}{N_{e} \times Q_{P A V G}} \times 100 \\
\text { Absolute peak time error (h): } E_{T}=\frac{\sum_{k=1}^{N_{e}}\left|T_{P k}-T_{P S k}\right|}{N_{e}}
\end{array}
$$

where $N_{e}$ is the number of events (15 here), $Q_{P k}$ is the observed peak discharge of the $k^{t h}$ event $\left(\mathrm{m}^{3} / \mathrm{s}\right), Q_{P S k}$ is the simulated peak, $Q_{P A V G}$ is the averaged observed peak discharge over the $N_{e}$ events, $T_{P k}$ is the observed time to the $k^{\text {th }}$ peak, $T_{P S k}$ is the simulated time to the $k^{\text {th }}$ peak.

Note that the models were calibrated only on downstream flows. The two other stations are considered ungauged for calibration, with blind simulations, so that the robustness of the method can be tested on these points. 


\section{Results and Discussion}

This section discusses the results obtained by applying the coupled model with two different formulations and six levels of lateral inflows distribution. The objective was to quantify the sensitivity of the model's results to different coupling options. The presentation of the results focuses first on identifying the best type of lateral inflow scheme and second on the optimal spatial aggregation for these inflows.

5.1 What type of lateral inflow scheme should be used? Point vs uniformly distributed strategies

\subsubsection{Model Performance}

Starting from the observation that hydraulic models use both types of lateral inflows, we compared the respective merits of the two coupling options presented in Section 4: the first option integrates point and uniformly distributed inflows, whereas the second option uses only point inflows. Figures 5, 6 and 7 show the three performance criteria (NSE, $E_{P}$ and $E_{T}$, as defined in Section 4) for the two lateral inflow formulations and six levels of inflow aggregation with 1 to 6 tributaries considered.

The results show that both coupling options lead to similar performance. Table 2 summarises the best level of performance that can be expected from the two options regardless of their spatial distribution. At the Tahlequah station, option 1 including point and distributed inflows provided slightly better values for the three criteria. At the Siloam Springs station, the same option 
was better on $N S E$ and $E_{T}$ but worse on $E_{P}$. At the Kansas station, it was significantly better for $N S E$ and $E_{T}$ but worse for $E_{P}$. Therefore, option 1 is better but does not outperform option 2. This result was quite a surprise: lower performance was expected for the point inflow options. Indeed, there are important differences between the two inflow distribution strategies and option 1 did appear much more realistic. Even when six tributaries were introduced in the modelling scheme, the intermediate area covered $682 \mathrm{~km}^{2}$ out of the $2025 \mathrm{~km}^{2}$ drained by the river reach (see Figure 1.b). This intermediate area was not explicitly modelled in option 2 (tributary inflows are rescaled to account for it as per equation 1). This could have caused significant differences in performance with option 1 , but the results did not confirm this possibility.

Simulations at the Kansas station are of poorer quality than at the Siloam Springs and Tahlequah stations: the figures given in Table 2 reveal that NSE is lower by 0.1 points and $E_{P}$ is greater by $10 \%$. This clearly indicate that simulating flow on tributaries is more difficult than on the river reach itself. We should not forget that along the main river channel, we combined two data: propagated observed upstream flows and lateral inflows calculated by the RR models. On tributaries, simulations made by the RR models only rely on rainfall data. This result may indicate that simulating flow on ungauged catchments may be significantly improved when both observed upstream discharges and rainfall are available rather than only rainfall.

A detailed analysis of simulated hydrographs confirms the previous state420 ments. An example is given in Figure 8 with the observed and simulated hydrographs in validation mode at the Tahlequah, Siloam Springs and Kansas stations for the 3 events having the largest peakflows in Tahlequah (events no. 2, 7 and 11, see Table 1). Options 1 and 2 were considered with a spatial 
resolution including two tributaries. In general, the two inflows options led to similar hydrographs with a slight advantage for option 1, as can be noted in Figure 8.b, 8.c, 8.d and 8.e.

Although both strategies are close in terms of performance criteria, they are not similarly robust: the drop in performance between calibration and validation was smaller for option 1, which is therefore more robust. This is clearly shown by the NSE values obtained at the Tahlequah (see Figure 5.a and Figure 5.b) and Siloam Springs (see Figure 5.c and Figure 5.d) stations. NSE values show similar values in calibration and validation mode for option 1 , whereas they deteriorated in validation for option 2. Hence, using uniformly distributed inflows strengthens the model's robustness.

\subsubsection{Model Parameters}

Figure 9 presents the values of the six calibrated parameters for all the coupling options. Since they characterise the propagation along the river channel, celerity and diffusion should not be dependent on the lateral inflows configuration. Celerity $(C)$ seems to follow this expected behaviour with limited variations between the various configurations (see Figure 9.i and 9.j). However, when the diffusion coefficient $(D)$ was calibrated in the point inflow scenario, its value decreased with the increase in the number of tributaries (see Figure 9.1). Indeed, when a limited number of tributaries was used within the point inflows option, lateral contributions were concentrated in a few points, leading to peaky inflow hydrographs. High values of the diffusion coefficient are then required to attenuate the routed hydrograph and obtain acceptable downstream simulations. Conversely, this parameter (see Figure 9.k) remains 
stable with uniformly distributed inflows whatever the spatial configuration may be.

Moreover, the coupled model was alternatively calibrated on each sub-period. One could analyse the stability of the parameters between sub-periods, which is another useful criterion to judge calibration quality. For three of the GR4J parameters, namely IGF (see Figure 9.c and 9.d), $R$ (Figure 9.e and 9.f) and TB (Figure 9.g and 9.h), uniformly distributed inflows reduced the uncertainty of parameter estimation. The values obtained on both sub-periods are in better agreement when this type of inflow was used than with the point inflow scenario.

To summarise, although both lateral inflow schemes appeared equivalent in terms of performance on this case study, further analysis revealed important differences: uniformly distributed inflow increases the stability of the results and the parameters, which is of primary importance when applying the model in operational conditions. Hence this type of configuration should be preferred to set up a hydraulic model on the Illinois River.

\subsection{How Many Lateral Tributaries Should Be Accounted For?}

\subsubsection{Influence of the number of tributaries}

Figures 5, 6 and 7 indicate that the two lateral inflow schemes differ in performance when additional tributaries are inserted.

Option 1, which uses both types of inflows, shows moderately improved performance between low (one tributary) and high (six tributaries) inflow resolution: 
470 at the Tahlequah (see Figure 5.b) and Siloam Springs stations (see Figure 5.d), the Nash-Sutcliffe efficiency (NSE) in validation mode improved by less than 0.02. The same observation applies to peak errors $\left(E_{P}\right)$ and peak time errors $\left(E_{T}\right)$ for Tahlequah (see Figures 6.b and 7.b). Conversely, $E_{P}$ at Siloam Springs and the three criteria at Kansas showed greater variations. the simulations on tributaries require different configurations compared to the ones on the main channel. The insertion of 4 tributaries is required to reach the maximum level of performance with option 1 (see Figure 5.f). It should be noted that the simulations on the second tributary, where Kansas is located, benefited from the recalibration of the GR4J parameters as the smaller tributaries (3 and 4$)$ were inserted into the system. The addition of tributaries 3 and 4 did not provide significant performance gain for the simulations at Siloam Springs and Tahlequah..

In the case of option 1 , the main result is that optimal lateral inflow resolution depends on the location of the simulation point. With target points on the main channel, resolution may be lower (only two or three point inflows are needed) than for points located on tributaries. As indicated in the previous section, simulations on tributaries are generated on the sole basis of rainfall inputs, whereas on the main channel, routed upstream flows can be used as an additional source of information. This could explain why fine resolutions are less necessary when simulating on the river reach itself.

With the second option that uses only point inflows, it is more difficult to identify an optimal lateral inflow resolution because the results do not vary monotonically. Unexpected results were obtained, such as the drop in the NSE 
criterion by 0.04 at Siloam Springs when adding the third tributary (Figure 5) and the 5\% drop in EP at Tahlequah when adding the second tributary. More surprisingly, the best performance is not always obtained with the highest level of inflow resolution: the best $N S E$ and $E_{P}$ in validation mode at Tahlequah comes with the second tributary. It appears that, with the point inflow option, introducing additional tributaries that are modelled individually may degrade the quality of simulations.

\subsubsection{Influence of the choice of tributaries}

The previous results raise the question of tributary ordering: as indicated in Section 4, tributaries are ordered by catchment area to first introduce large contributions and then refine by adding smaller ones. The results mentioned previously reveal that this strategy might not be optimal, at least for option 2. To check this point, we compared this strategy with all possible combinations of a fixed number of tributaries selected among the six identified on Figure 1. The performance criteria were then calculated for each combination and compared with the value obtained with the initial catchment ordering strategy.

Figure 10 shows the mean NSE values over the two sub-periods obtained in validation mode obtained after calibrating the coupled model with all possible combinations of three tributaries among the six previously defined (a total of 51520 calibration exercises were performed). Similar figures would be obtained with another number of tributaries.

This figure helps us address the difficult question of choosing the right set of tributaries. The results of the two lateral inflow options are classified by 
decreasing NSE values. Rank 1 gives the best option for the coupled model.

In addition, circles and squares indicate the position of the combinations using tributaries by catchment area order, which was the hypothesis made in the previous sections.

This figure confirms what had already been pointed out regarding the two options. First, including uniformly distributed inflows makes the coupled model less dependent on the choice of tributaries injected as point inflows: on all the graphs, curves related to option 1 show smaller loss of performance when sub-optimal configurations were selected compared to option 2. For example, with a three point inflow scheme, the NSE at the Tahlequah station (see Figure 10.a) showed very limited variations for the different combinations with option 1 but dropped by more than 0.15 for option 2 .

Second, the hypothesis of integrating tributaries as point inflows by order of catchment area seems valid for option 1 but not for option 2: the circles representing the model performance using tributaries ordered by catchment area rank first on most graphs. This confirms the value of catchment area order for option 1. Conversely, this order is seriously challenged in option 2. As a result, the comparison presented in Section 5.1 is probably not very fair to option 2 because better simulations can be achieved with alternative tributary combinations. The results of option 2 improved, but Figure 10 reveals that they never surpassed those of option 1.

Third, this confirms the different behaviour for simulations on points located on the main channel and on the tributary: in this second case, even option 1 is sensitive to the choice of tributaries.

The analysis illustrated in Figure 10 provides a second important result: the 
optimal selection of point inflow tributaries was easier when uniformly distributed lateral inflows were taken into account. Conversely, the point inflow option required studying a large number of tributary combinations to identify the optimal one.

\section{Conclusion}

This article has investigated the coupling of lumped rainfall-runoff and hydraulic models. The motivation was to clarify the methods to be used for generating inflows to the hydraulic model and to quantify the impact of different options available when such tools are used to simulate flows on a river reach. Two important questions were addressed: (1) How should RR models be connected to hydraulic models? Should the connections be point or uniformly distributed? (2) How many point connections should be introduced to reach an acceptable level of performance? These questions were investigated by applying the GR4J lumped RR model and the linearised diffusive wave routing model on a 95-km reach of the Illinois River within the DMIP 2 study area. Coupled models were calibrated with two options for the lateral scheme (point inflows only or point and uniformly distributed inflows combined) and six levels of inflow resolution (one to six tributaries).

The main findings of this study can be summarised as follows:

- Uniformly distributed inflows lead to more robust and stable coupled models. A similar level of performance can be reached with models using point inflows only, but less stable performance and parameters between sub-periods were observed, with increased risks of undesired parameter com- 
pensations.

- The identification of the optimal number of tributaries is easier when a combination of uniformly distributed and point inflows is used. In this case, model performance was not very sensitive to this factor and the inclusion of two or three tributaries appeared sufficient for simulating flow on the main channel. In contrast, this selection can be much more difficult with point inflow models because a large number of combinations need to be tested to identify the optimal one.

- The simulation on the main channel differed from the simulation on one tributary: the overall performance is higher on the main channel and requires a lesser degree of lateral inflow resolution. The best performance on the tributary was obtained when the highest number of tributaries were included in the model.

The authors acknowledge that the methods analysed in this article should be tested on a larger number of catchments to reach more general conclusions. The extension of these results to a database of 50 catchments located in France was investigated by Lerat (2009), who obtained similar conclusions, to be reported in the near future.

585 This work opens several perspectives that may clarify the methods used in coupling rainfall-runoff models and hydraulic models. First, we used a linearised diffusive wave model based on a simplification of the Saint-Venant equation system. The methods presented in this paper should now be applied with a fully dynamic model. Second, we did not investigate the impact of rainfall input quality and the complexity of model parameterisation. Finally, the longterm objective of this study was to propose robust methods to apply coupled models to flood forecasting. This paper only covered the simulation mode wi- 
thout using assimilation algorithms. The forecasting mode will be the next step and the results will be reported in due course. 
Ajami, N., Gupta, H., Wagener, T., Sorooshian, S., 2004. Calibration of a semi-distributed hydrologic model for streamflow estimation along a river system. J. Hydrol. 298 (1-4), 112-135.

Andréassian, V., Oddos, A., Michel, C., Anctil, F., Perrin, C., Loumagne, C., 2004. Impact of spatial aggregation of inputs and parameters on the efficiency of rainfall-runoff models: A theoretical study using chimera watersheds. Water Resour. Res. 40 (5).

Andréassian, V., Bergström, S., Chahinian, N., Duan, Q., Gusev, Y., Littlewood, I., Mathevet, T., Michel, C., Montanari, A., Moretti, G., et al., 2006. Catalogue of the models used in MOPEX 2004/2005. IAHS publication 307, $41-93$.

Baptista, M., Michel, C., 1989. Une utilisation simple du modèle hayami en hydrologie. La Houille Blanche 2, 123-130.

Beven, K., 1996. The limits of splitting: Hydrology. The Science of the Total Environment 183 (1-2), 89-97.

Birkhead, A. L., James, C. S., 2002. Muskingum river routing with dynamic bank storage. J. Hydrol. 264 (1-4), 113-132.

Boyle, D. P., Gupta, H. V., Sorooshian, S., Koren, V., Zhang, Z., Smith, M., 2001. Toward improved streamflow forecasts: Value of semidistributed modeling. Water Resour. Res. 37 (11), 2749-2759.

Butts, M. B., Payne, J. T., Kristensen, M., Madsen, H., 2004. An evaluation of the impact of model structure on hydrological modelling uncertainty for streamflow simulation. J. Hydrol. 298 (1-4), 242-266.

Corradini, C., 1991. Evaluation of alternative configurations of basin elements for on-line flood forecasting. Water Resources Bulletin 27 (3), 407-418. 
Das, T., Bárdossy, A., Zehe, E., He, Y., 2008. Comparison of conceptual model performance using different representations of spatial variability. J. Hydrol. 356 (1-2), 106-118.

Fan, P., Li, J. C., 2006. Diffusive wave solutions for open channel flows with uniform and concentrated lateral inflow. Advances in Water Resources 29 (7), 1000-1019.

Havnø, K., Madsen, M. N., Dørge, J., 1995. Mike 11 - a generalized river modelling package. In: Singh, V. P. (Ed.), Computer Models of Watershed Hydrology. Water Resources Publications, Highlands Ranch, USA, pp. 733782.

Hayami, S., 1951. On the propagation of flood waves. Bulletin, Disaster Prevention Research Institute, Kyoto University, Japan 1.

Klemes, V., 1983. Conceptualization and scale in hydrology. J. Hydrol. 65 (13), 1-23.

Klemes, V., 1986. Operational testing of hydrological simulation models. Hydrol. Sciences Journal 31 (1), 13-24.

Knebl, M. R., Yang, Z., Hutchison, K., Maidment, D. R., 2005. Regional scale flood modeling using NEXRAD rainfall, GIS, and HEC-HMS/ RAS: A case study for the San Antonio River Basin Summer 2002 storm event. Journal of Environmental Management 75 (4 SPEC. ISS.), 325-336.

Koren, V., Finnerty, B., Schaake, J., Smith, M., Seo, D., Duan, Q., 1999. Scale dependencies of hydrologic models to spatial variability of precipitation. J. Hydrol. 217 (3-4), 285-302.

Koren, V., Reed, S., Smith, M., Zhang, Z., Seo, D.-J., 2004. Hydrology la645 boratory research modeling system (HL-RMS) of the US national weather service. J. Hydrol. 291 (3-4), 297-318.

Krysanova, V., Bronstert, A., Muller-Wohlfeil, D., 1999. Modelling river di- 
scharge for large drainage basins: from lumped to distributed approach. Hydrol. Sciences Journal 44 (2), 313-331.

650

Moussa, R., 1997. Geomorphological transfer function calculated from digital elevation models for distributed hydrological modelling. Hydrol. Processes $11,429-449$.

Nash, J. E., Sutcliffe, J. V., 1970. River flow forecasting through conceptual models. part 1: a discussion of principles. J. Hydrol. 10 (3), 282-290.

Onyando, J. O., Schumann, A. H., Schultz, G. A., 2003. Simulation of flood 
hydrographs based on lumped and semi-distributed models for two tropical catchments in kenya. Hydrol. Sciences Journal 48 (4), 511-524.

Perrin, C., Michel, C., Andréassian, V., 2003. Improvement of a parsimonious model for streamflow simulation. J. Hydrol. 279 (1-4), 275-289.

Reed, S., Koren, V., Smith, M., Zhang, Z., Moreda, F., Seo, D.-J., 2004. Overall distributed model intercomparison project results. J. Hydrol. 298 (1-4), 2760.

Refsgaard, J., 1997. Parameterisation, calibration and validation of distributed hydrological models. J. Hydrol. 198 (1-4), 69-97.

Refsgaard, J. C., Knudsen, J., 1996. Operational validation and intercomparison of different types of hydrological models. Water Resour. Res. 32 (7), $2189-2202$.

Robinson, J., Sivapalan, M., 1995. Catchment-scale runoff generation model by aggregation and similarity analyses. Hydrol. Processes 9 (5-6), 555-574. Savenije, H., 2001. Equifinality, a blessing in disguise? Hydrol. Processes $15(14)$.

Sivapalan, M., Bloschl, G., Zhang, L., Vertessy, R., 2003. Downward approach to hydrological prediction. Hydrol. Processes 17 (11), 2101-2111.

Smith, M., Koren, V., Reed, S., Zhang, Z., Zhang, Y., Moreda, F., Cui, Z., Mizukami, N., Sheldon, S., 2009. The Distributed Model Intercomparison Project: Phase 2 Motivation and Experiment Design. J. Hydrol. in press.

Smith, M. B., Seo, D. ., Koren, V. I., Reed, S. M., Zhang, Z., Duan, Q., Moreda, F., Cong, S., 2004. The distributed model intercomparison project (dmip): Motivation and experiment design. J. Hydrol. 298 (1-4), 4-26.

Te Linde, A., Aerts, J., Hurkmans, R., Eberle, M., 2008. Comparing model 700 performance of two rainfall-runoff models in the Rhine basin using different atmospheric forcing data sets. Hydrology and Earth System Sciences 12 (3), 
943-957.

USACE, 2002. HEC-RAS River Analysis System: Hydraulic Reference Manual. Tech. rep., US Army Corps of Engineers.

Vázquez, R., Feyen, L., Feyen, J., Refsgaard, J., 2002. Effect of grid size on effective parameters and model performance of the MIKE-SHE code. Hydrological Processes 16 (2).

Vieux, B., 1993. DEM aggregation and smoothing effects on surface runoff modeling. Journal of Computing in Civil Engineering 7 (3), 310-338.

Whiteaker, T. L., Robayo, O., Maidment, D. R., Obenour, D., 2006. From a nexrad rainfall map to a flood inundation map. Journal of Hydrologic Engineering 11 (1), 37-45.

Wood, E. F., Sivapalan, M., Beven, K., Band, L., 1988. Effects of spatial variability and scale with implications to hydrologic modeling. J. Hydrol. $102(1-4), 29-47$.

Young, P., 2003. Top-down and data-based mechanistic modelling of rainfallflow dynamics at the catchment scale. Hydrol. Processes 17 (11).

Zhang, Z., Koren, V., Smith, M., Reed, S., Wang, D., 2004. Use of next generation weather radar data and basin disaggregation to improve continuous hydrograph simulations. Journal of Hydrologic Engineering 9, 103-115. 

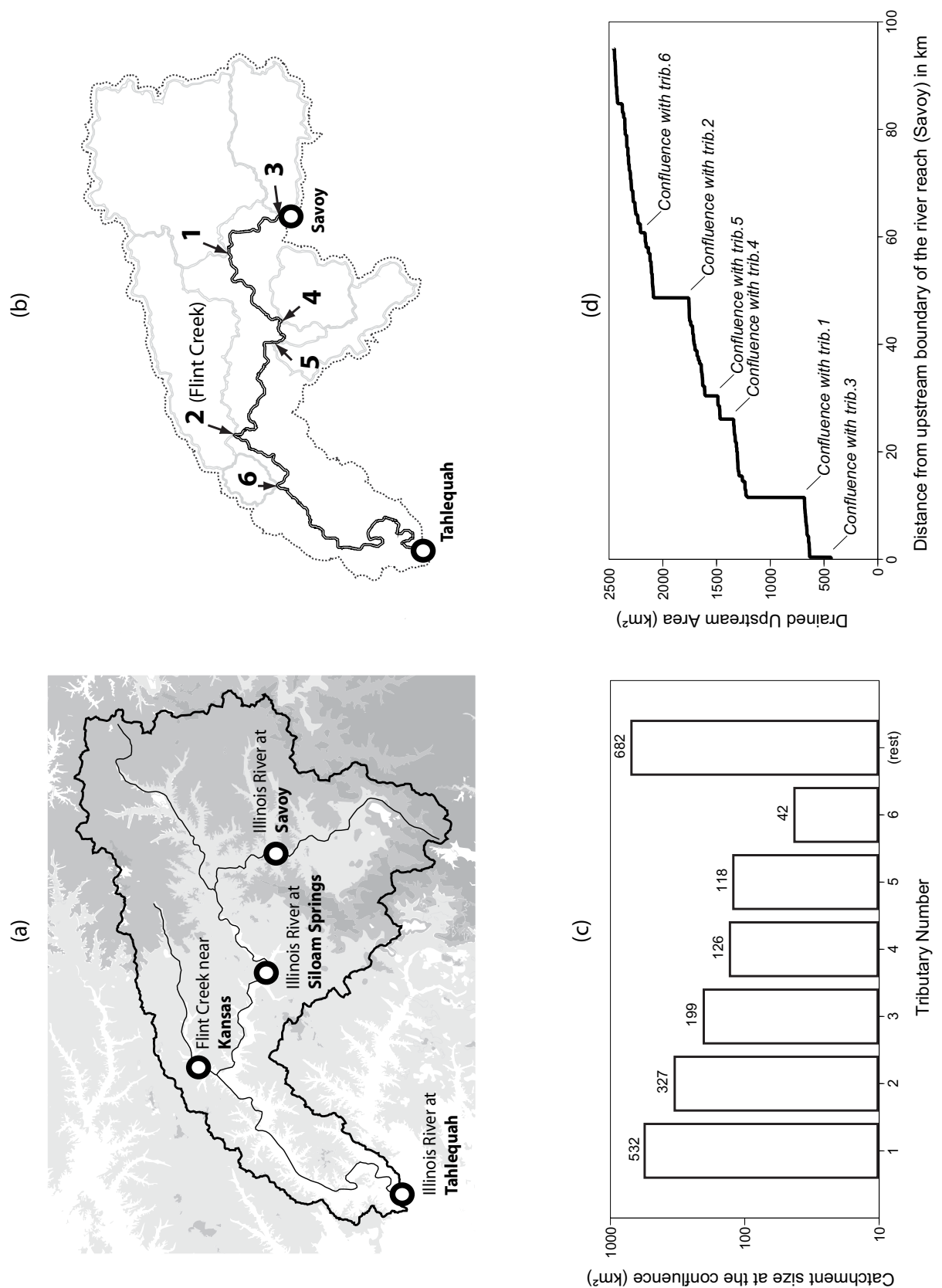

Figure 1. (a) Location of the different stations: the upstream boundary of the river reach is located on the Illinois River at Savoy and the downstream end at Tahlequah. Interior simulations were analysed on the main channel at Siloam Springs and on a tributary of the Illinois River (Flint Creek) at Kansas. (b) Catchment boundaries of the six largest tributaries. (c) Catchment area (in $\mathrm{km}^{2}$ ). (d) Changes in the drained area from the Savoy station to the Tahlequah station plotted against the hydraulic distance from the Savoy station. 


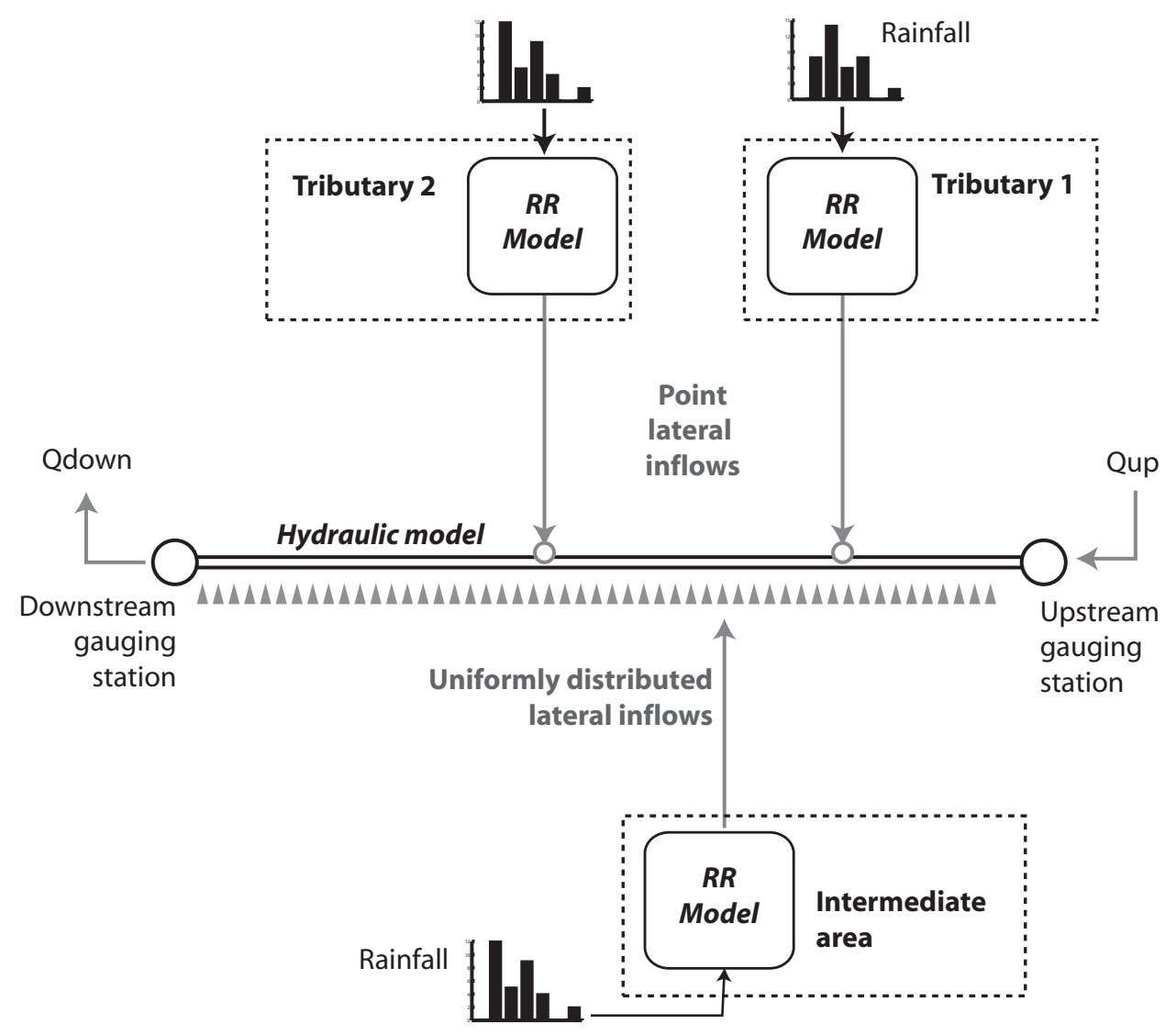

Figure 2. Scheme applied to couple the lumped rainfall-runoff model and the hydraulic model. 

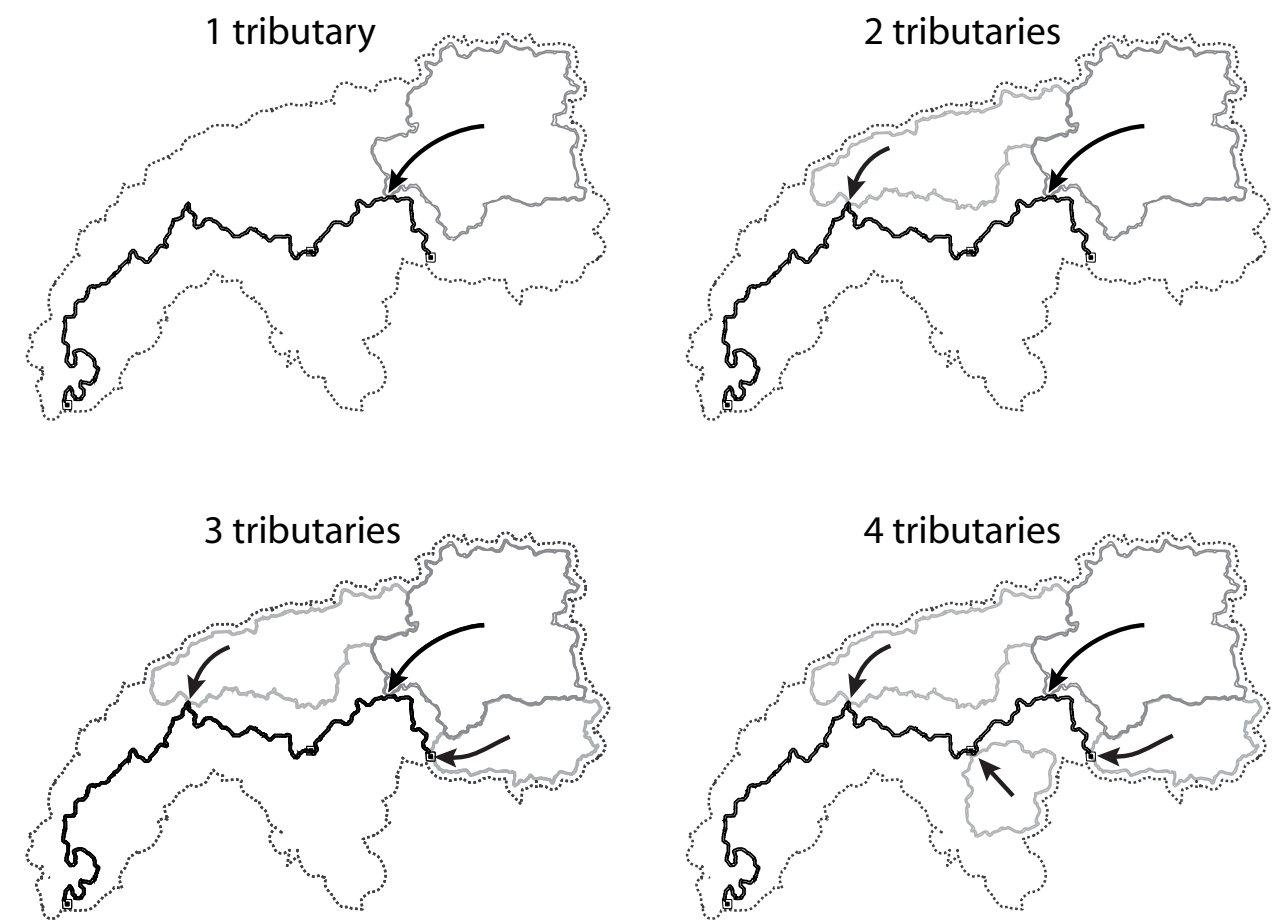

Figure 3. Different options regarding the spatial discretisation of lateral inflows.

Tributaries are progressively inserted as point lateral inflows by order of decreasing catchment area. The figure shows the introduction of the first four tributaries 


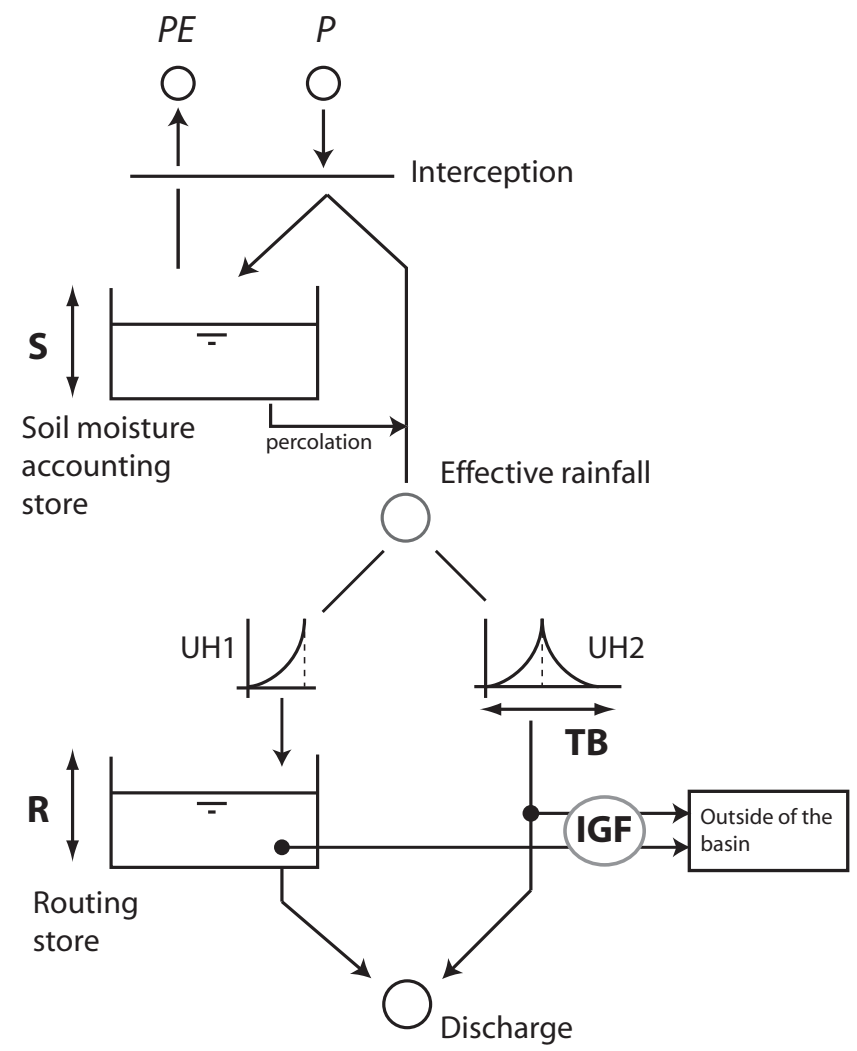

Figure 4. GR4J rainfall-runoff model scheme (P: precipitation; PE: potential evapotranspiration; S, R, TB and IGF: the 4 model parameters) 
(a) Tahlequah, Calibration

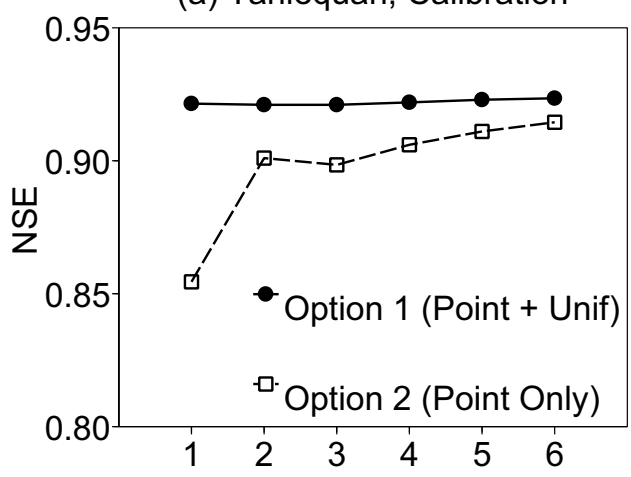

(c) Siloam Springs, Calibration

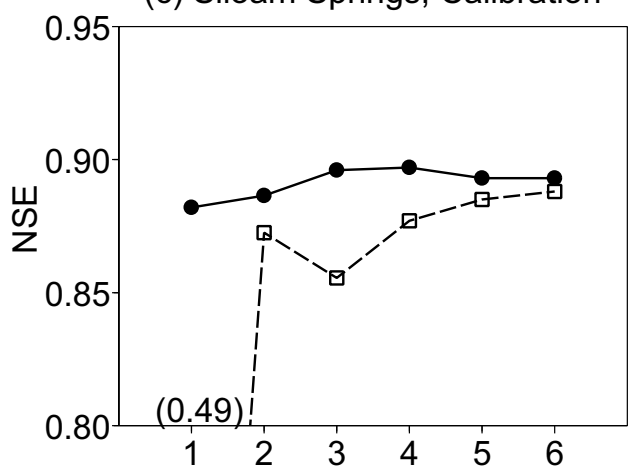

(e) Kansas, Calibration

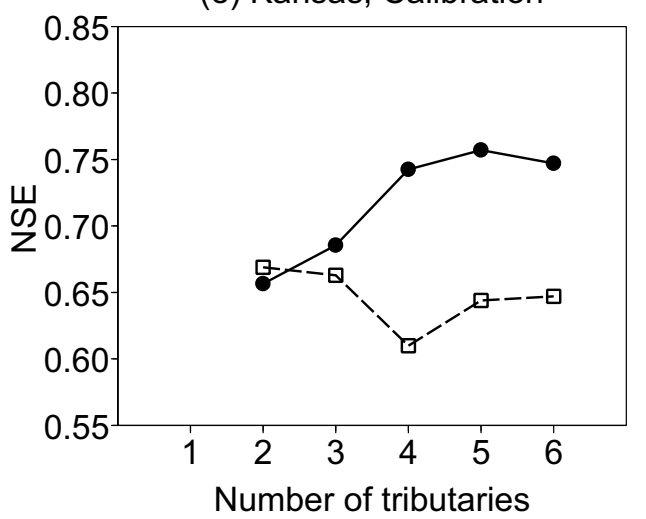

(b) Tahlequah, Validation

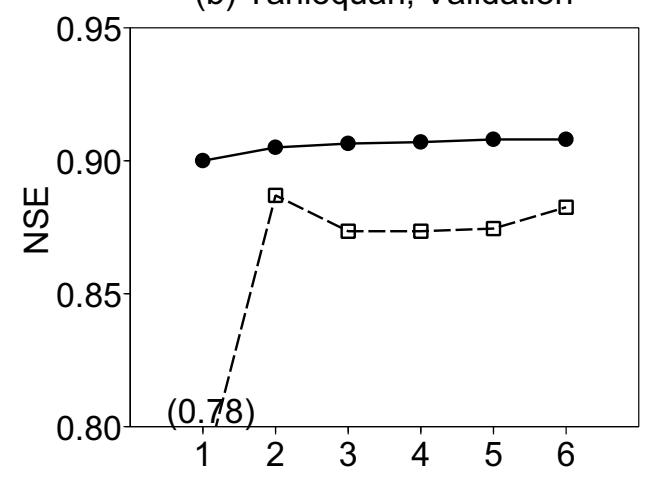

(d) Siloam Springs, Validation


Figure 5. Nash-Sutcliffe efficiencies (NSE) averaged over the two sub-periods in calibration and validation mode at the Tahlequah (downstream end of the reach), Siloam Springs (interior of the reach) and Kansas (tributary) stations with an increasing number of tributaries modelled individually. Two options were considered for the lateral inflow scheme: option 1 makes use of point and uniformly distributed inflows, option 2 uses only point inflows. The criteria were not calculated at the Kansas station for the configuration having only one tributary (see section 4). 
(a) Tahlequah, Calibration

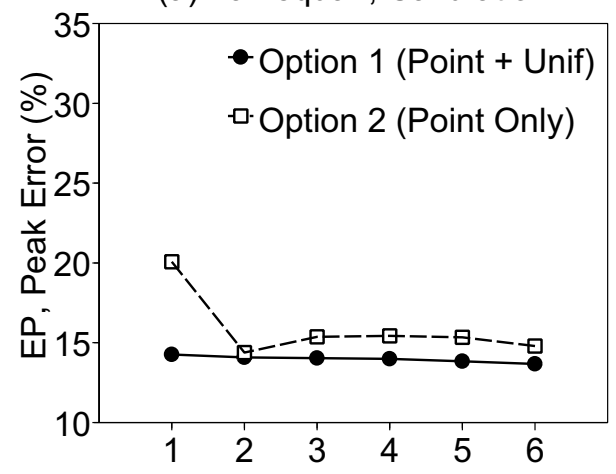

(c) Siloam Springs, Calibration

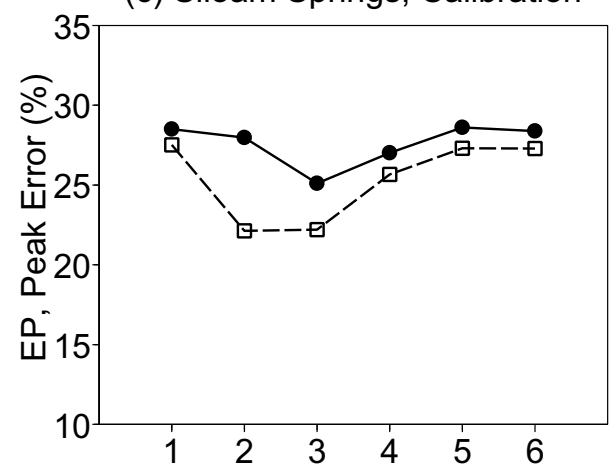

(e) Kansas, Calibration

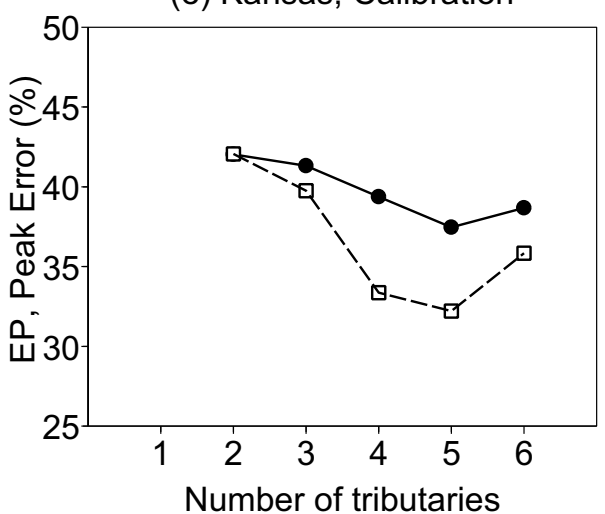

(b) Tahlequah, Validation



(d) Siloam Springs, Validation

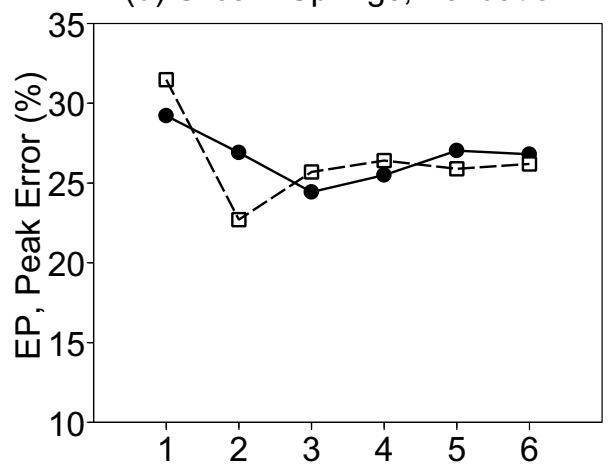

(f) Kansas, Validation

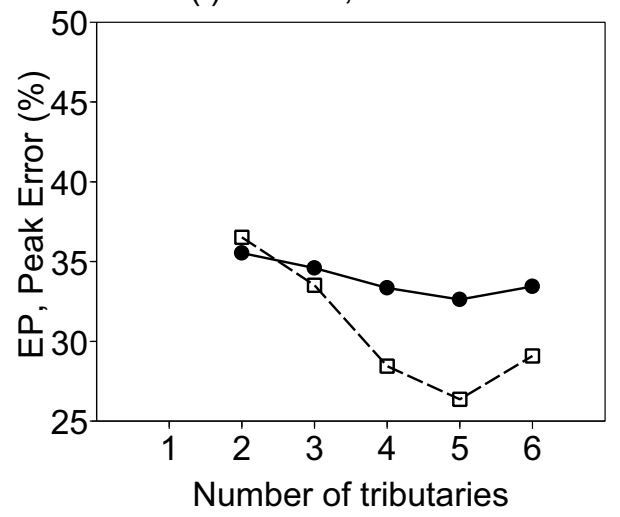

Figure 6. Mean peak error $\left(E_{P}\right)$ averaged over the two sub-periods in calibration and validation mode at the Tahlequah (downstream end of the reach), Siloam Springs (interior of the reach) and Kansas (tributary) stations with an increasing number of tributaries modelled individually. The mean peak error was calculated on the 15 events listed in Table 1. The criteria were not calculated at the Kansas station for the configuration having only one tributary (see Section 4). 
(a) Tahlequah, Calibration



(c) Siloam Springs, Calibration

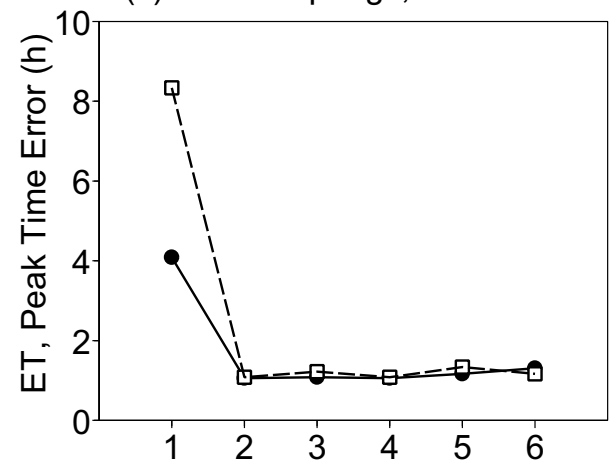

(e) Kansas, Calibration

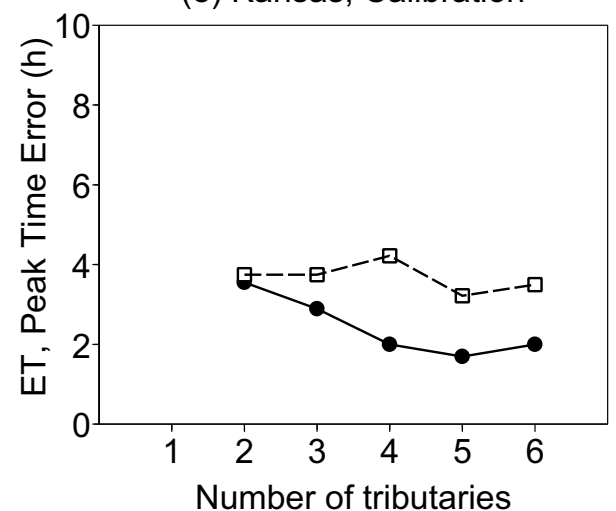

(b) Tahlequah, Validation



(d) Siloam Springs, Validation

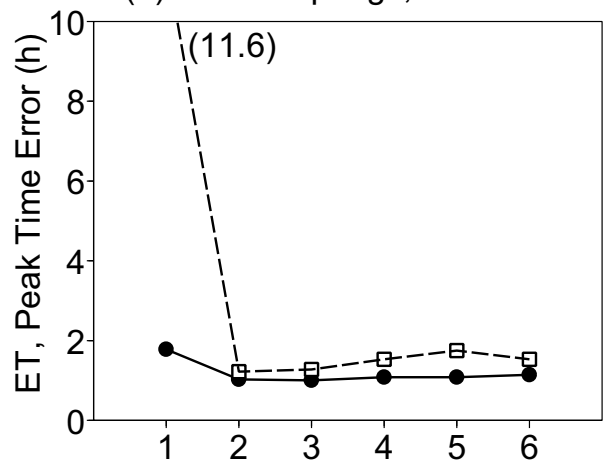

(f) Kansas, Validation

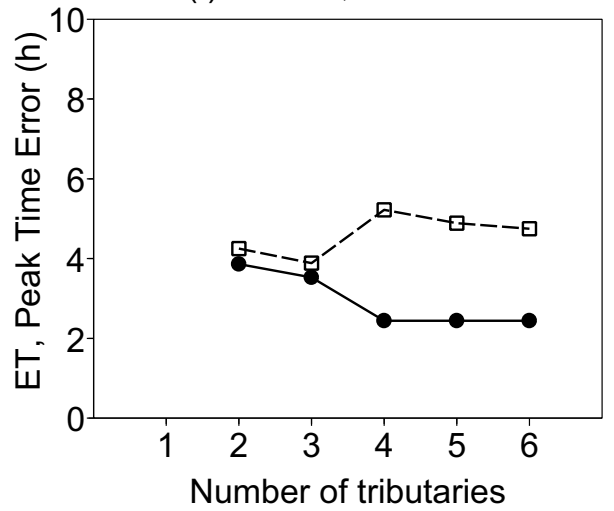

Figure 7. Mean peak time error $\left(E_{T}\right)$ averaged over the two sub-periods in calibration and validation mode at the Tahlequah (downstream end of the reach), Siloam Springs (interior of the reach) and Kansas (tributary) stations with an increasing number of tributaries modelled individually. The mean peak time error was calculated on the 15 events listed in Table 1 . The criteria were not calculated at the Kansas station for the configuration having only one tributary (see section 4). 
(a) Tahlequah, Event no. 2
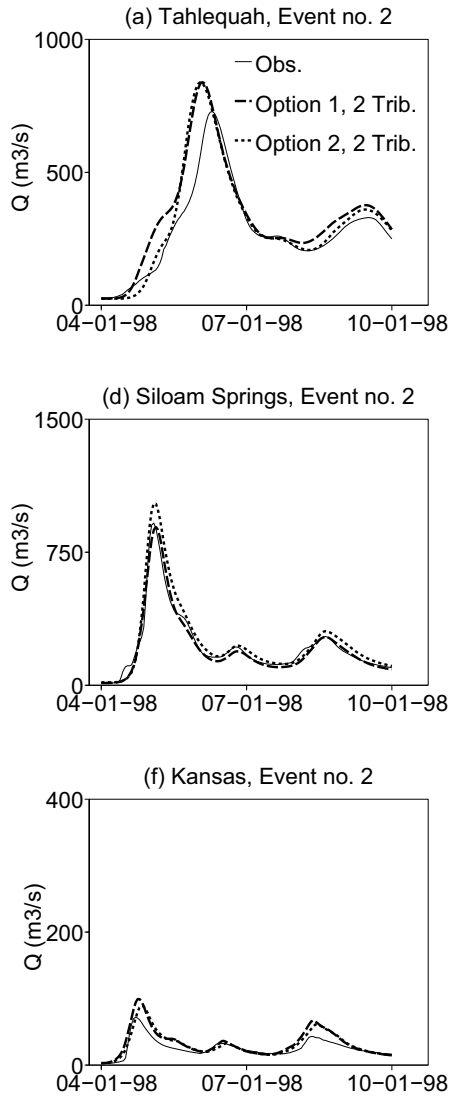

(b) Tahlequah, Event no. 7



(e) Siloam Springs, Event no. 7



(g) Kansas, Event no. 7

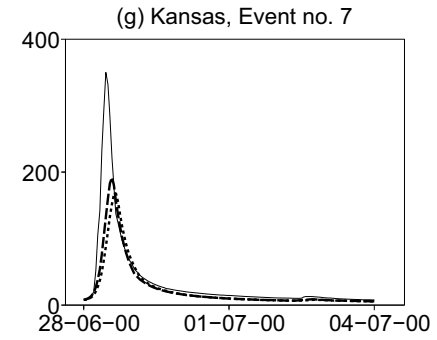

(c) Tahlequah, Event no. 11
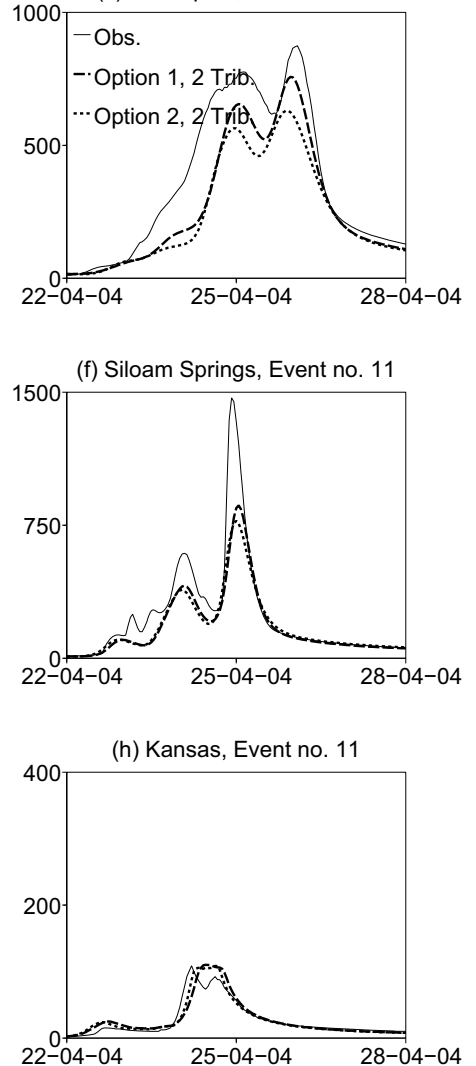

Figure 8. Observed and simulated hydrographs in validation mode for the events (no. 2, no. 7 and no. 11) having the three largest peakflows at Tahlequah station (729, 831 and $874 \mathrm{~m}^{3} / \mathrm{s}$ respectively; see Table 1$)$. Two options were considered for the lateral inflow scheme: option 1 makes use of point and uniformly distributed inflows, option 2 uses only point inflows. Both options were applied with a spatial configuration including two tributaries modelled individually. 
(a) Option 1 (Point+Unif. Distr. Inflows)

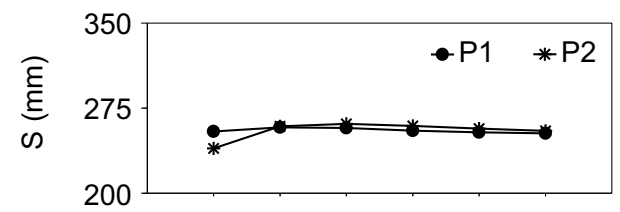

(c)

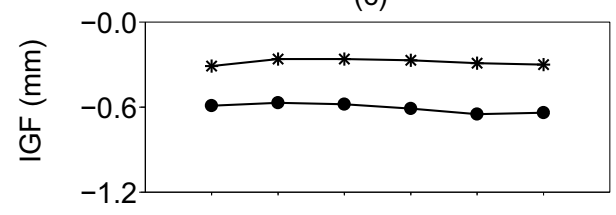

(e)

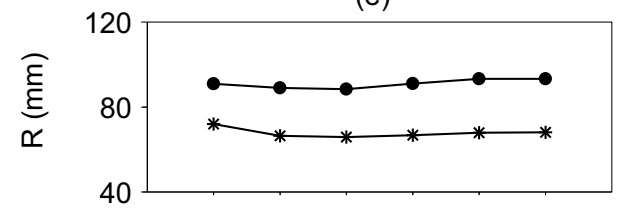

(g)

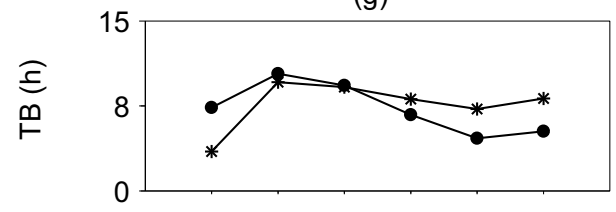

(i)

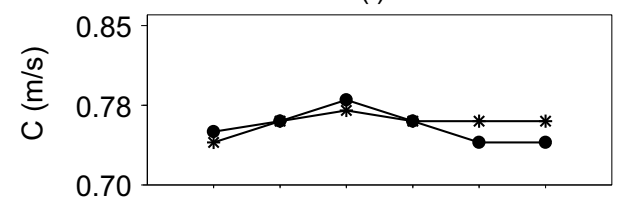

(k)

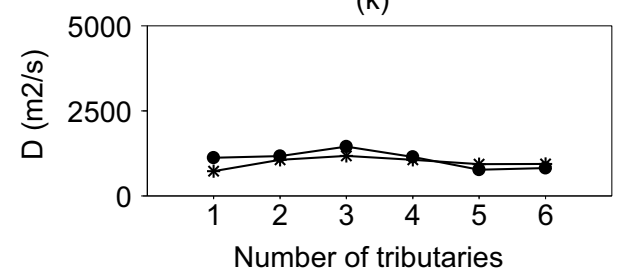

(b) Option 2 (Point Inflows only)

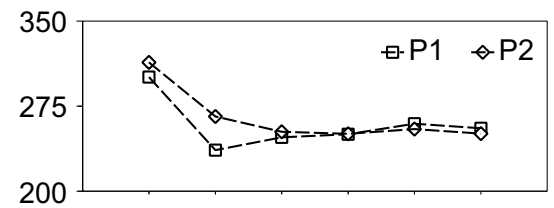

(d)



(f)

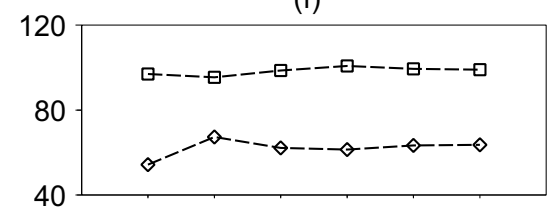

(h)

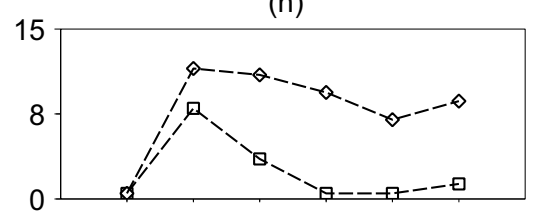

(j)

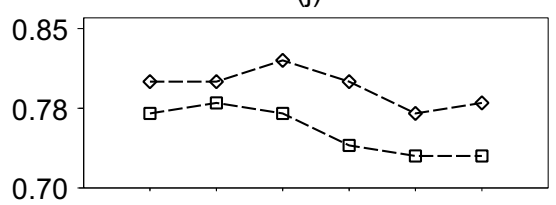

(l)



Figure 9. The parameters of the combined model obtained after a calibration on the two sub-periods P1 (1995-10-01 to 2002-09-30) and P2 (2001-10-01 to 2006-09-30) with varying levels of lateral inflow discretisation and two options for the lateral inflow scheme. The first four parameters are those of the GR4J lumped RR model $(S, I G F, R$ and $T B)$ and the last two are those of the linearised diffusive wave model $(C$ and $D)$. 
(a) Tahlequah

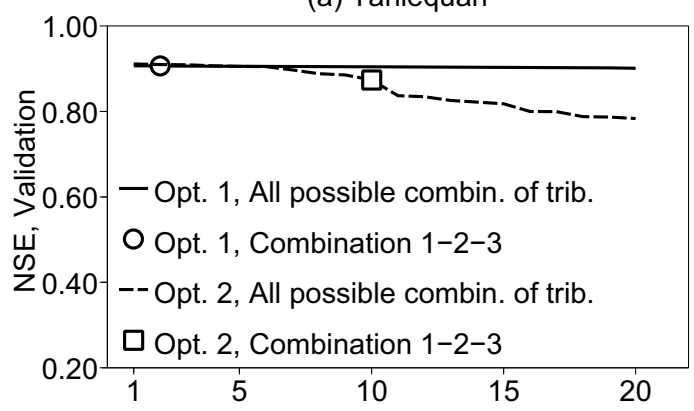

(b) Siloam Springs

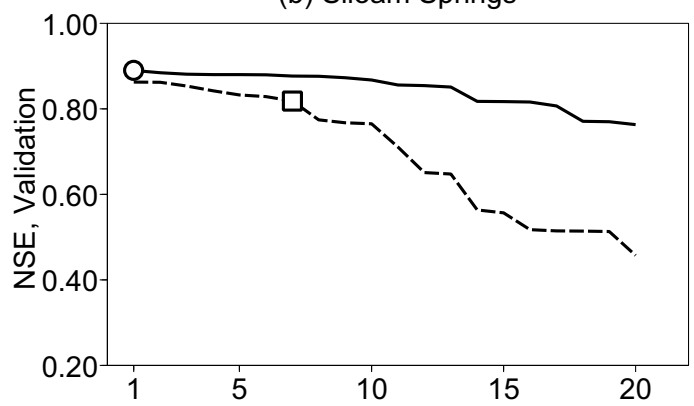

(c) Kansas

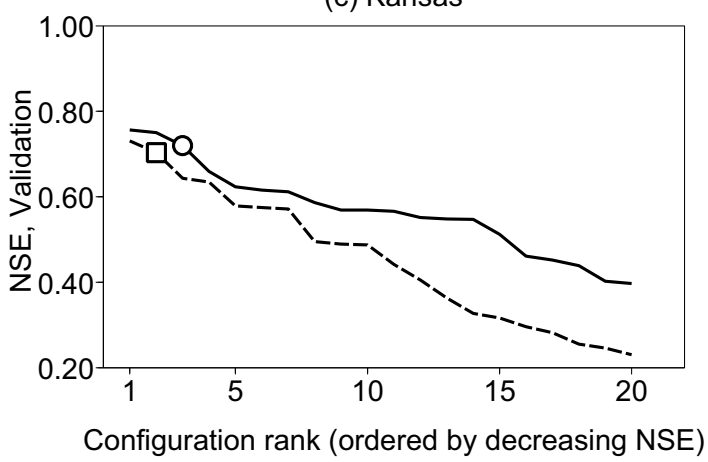

Figure 10. The Nash-Sutcliffe efficiencies (NSE) averaged over the two sub-periods in validation mode for the Tahlequah, Siloam Springs and Kansas stations with all possible combinations of three tributaries as point inflows and the two options of lateral inflow scheme. Circles $(O)$ and squares $(\square)$ indicate the performance of options 1 and 2, respectively, with tributaries considered by order of catchment area (configuration including the tributaries coded 1, 2 and 3 on Figure 1). 


\begin{tabular}{|c|c|c|c|c|}
\hline Event $\mathrm{Nb}$. & Start & End & $\begin{array}{c}\text { Peak flow } \\
\text { Savoy }\left(\mathrm{m}^{3} / \mathrm{s}\right)\end{array}$ & $\begin{array}{c}\text { Peak flow } \\
\text { Tahlequah }\left(\mathrm{m}^{3} / \mathrm{s}\right)\end{array}$ \\
\hline 1 & 1997-02-20 07:00 & 1997-02-26 18:00 & 274 & 597 \\
\hline 2 & 1998-01-04 01:00 & 1998-01-12 03:00 & 823 & 729 \\
\hline 3 & 1999-02-06 16:00 & 1999-02-11 21:00 & 150 & 276 \\
\hline 4 & 1999-05-04 02:00 & 1999-05-10 04:00 & 184 & 370 \\
\hline 5 & 1999-06-30 05:00 & 1999-07-05 10:00 & 350 & 556 \\
\hline 6 & 2000-06-17 05:00 & 2000-06-21 00:00 & 271 & 483 \\
\hline 7 & 2000-06-28 04:00 & 2000-07-02 13:00 & 580 & 831 \\
\hline 8 & 2001-12-15 22:00 & 2001-12-21 21:00 & 243 & 557 \\
\hline 9 & 2002-04-07 19:00 & 2002-04-12 21:00 & 303 & 561 \\
\hline 10 & 2004-03-03 15:00 & 2004-03-08 19:00 & 54 & 279 \\
\hline 11 & 2004-04-21 19:00 & 2004-04-29 07:00 & 1034 & 874 \\
\hline 12 & 2004-07-02 17:00 & 2004-07-07 21:00 & 232 & 515 \\
\hline 13 & 2004-10-31 22:00 & 2004-11-04 23:00 & 100 & 267 \\
\hline 14 & 2005-01-03 02:00 & 2005-01-09 19:00 & 203 & 600 \\
\hline 15 & 2005-01-12 15:00 & 2005-01-16 21:00 & 195 & 433 \\
\hline
\end{tabular}

Table 1

List of events used to compute the event-based statistics 


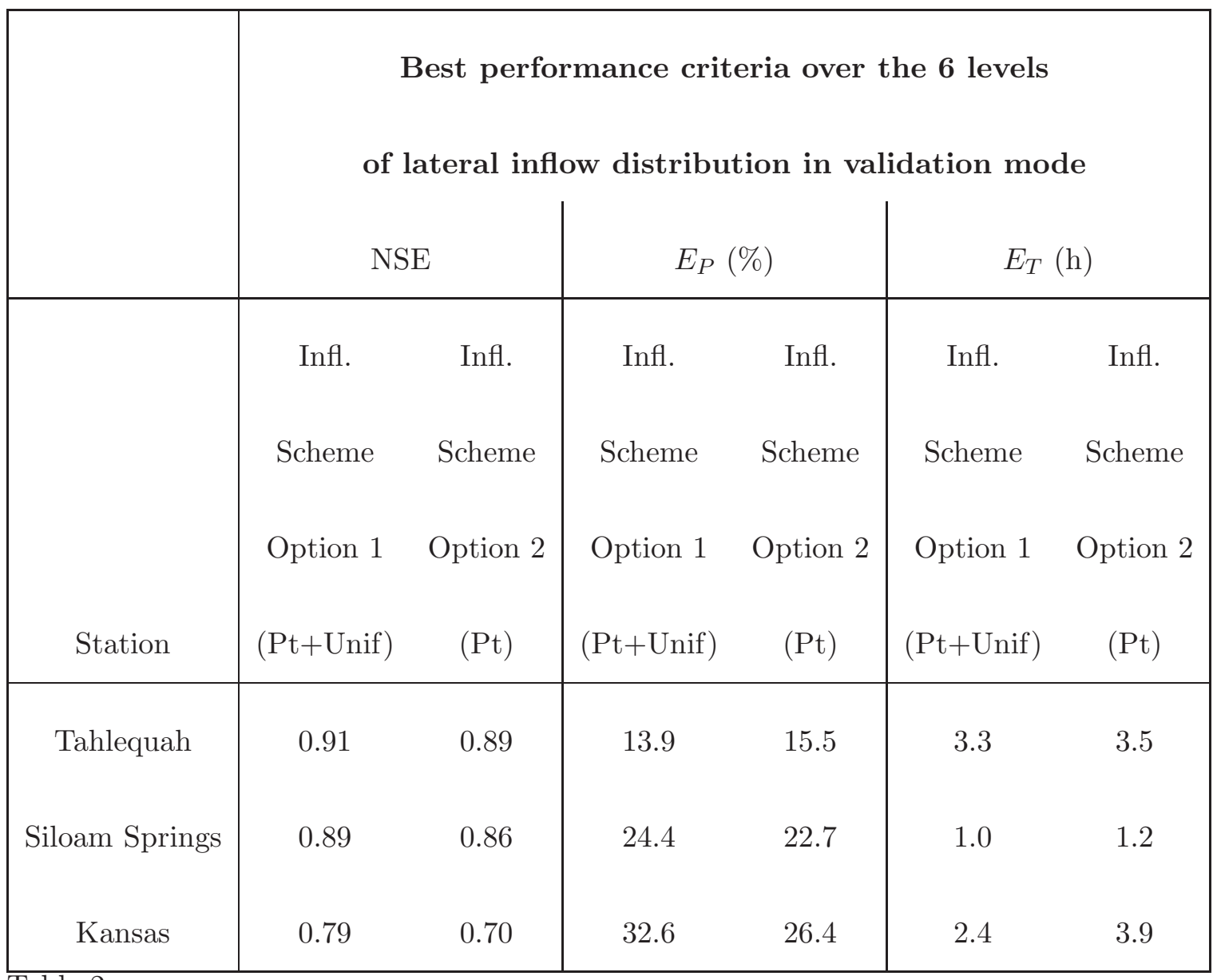

Table 2

Nash-Sutcliffe efficiency (NSE), absolute peak error $\left(E_{P}\right)$ and absolute peak time error $\left(E_{T}\right)$ averaged over the two sub-periods (1995-10-01 to 2002-09-30 and 200110-01 to 2006-09-30) in validation mode. Two options were used for the lateral inflow scheme: option 1 makes use of point and uniformly distributed inflows, option 2 uses only point inflows. Each value is the best criteria among the six configurations of lateral inflow distribution. The results for all lateral configurations are presented in Figures 5, 6 and 7 . 